\title{
Emissions and Performance analysis of variable compression ratio engine fuelled with safflower oil methyl ester-diesel blends
}

\author{
Pulkit Kumar*, K.P. Kolhe and S.S Ragit \\ JSPM's Imperial College of Engineering and Research, wagholi, Pune, India \\ Accepted 15 June 2016, Available online 20 June 2016, Special Issue-5 (June 2016)
}

\begin{abstract}
This paper presents the performance and emission characteristics of safflower oil bio-diesel blends in a 4-stroke single-cylinder water-cooled diesel engine. In this work safflower oil bio diesel is prepared by alkaline transesterification method. All experiments were carried out at constant speed of $1500 \mathrm{rpm}$ and the biodiesel blends were varied for B2O and B40. The engine was equipped with variable compressions ratio (VCR) mechanism. All the blends and pure diesel was checked on the engine at a load of $0 \mathrm{~kg}, 3 \mathrm{~kg}, 6 \mathrm{~kg}$ and $9 \mathrm{~kg}$ by varying the compression ratio. The change of compression ratio from 17 to 18 resulted in 6\% and $2 \%$ increase in brake thermal efficiency in case of blend B2O and B40 respectively. At all load condition, Blend B40 shows minimum fuel consumption as compared from blend $\mathrm{B} 2 \mathrm{O}$ and $\mathrm{B} 40$. On an average $\mathrm{CO}_{2}$ emissions reduced by $50 \%, \mathrm{NO}_{\mathrm{X}}$ emissions reduced by $45 \%, \mathrm{HC}$ emissions reduced by $40 \%$ and CO emissions reduced marginally when compression ratio was increased from 17 to 18 . From this work it has been concluded that blend B20 at compression ratio 17:1 can be used as an alternative fuel for diesel engine without modification.
\end{abstract}

Keywords: Safflower oil methyl ester, compression ratio, transesterification, specific fuel consumption, etc

\section{Nomenclature}

BTE Brake Thermal Efficiency

CO Carbon Monoxide

C02 Carbon Dioxide

SFC Specific Fuel Consumption

SOME Safflower Oil Methyl Ester

HC Hydrocarbons

NOX Nitrogen Oxide

\section{Introduction}

Increasing rate of petroleum products in India has led to a significant problem to find some alternative source which can fulfill the need of petrol and diesel. For sustainable development of India Energy, fuels and pollution are the major issues to tackle with. Energy sector is highly reliable on imports of petroleum products. Petroleum products import have increased by $170 \%$ in quantity and $363 \%$ by value from $2004-05$ to 2011-12. Mostly for a developing country like India , energy consumptions are directly linked with the use of diesel engine which are used in a various fields like Transport, Agriculture, Constructions, passenger cars, etc. But at the same time exhaust of diesel engine are rich source of air pollutants like SPM and NOx. Use of alternative technology and alternate fuels is a solution

*Corresponding author: Pulkit Kumar to overcome these issues. Again the feasibility of this type of fuels should be checked, then only it can be produced on a mass scale for commercial use making its price affordable for end users. The potential alternative fuels available are Liquefied Petroleum Gas (LPG), Alcohols (Methanol and Ethanol), Compressed Natural Gas (CNG), Hydrogen and Vegetable oils. Out of these alternatives, vegetable oil is one of the most important choices because of its properties to mix with diesel. The use of vegetable oils as engine fuels can help to reduce the environmental hazards of fossil fuels. Vegetable oils have good ignition characteristics but they also comes with some demerits like carbon deposits, high density, more molecular weight, high viscosity, lower calorific value and poor combustion. These problems lead to poor thermal efficiency. But these can be rectified by using techniques like Dilution (blending), Pyrolysis (cracking) ,Micro-emulsification and transestrification which reduces the viscosity of vegetable oils.

Biodiesel is fuel derived from renewable biological resources for use in diesel engines. It is a liquid fuel with similar combustion properties to petrol or diesel. This is why biodiesel is considered as an alternative source of energy that is produced from vegetable oils, animal fats and even used waste cooking oil. It can be made from the oils of vegetable products such as soybean, canola, sunflower, safflower and cotton, and also animal fat. 
In this work biodiesel is prepared by using safflower oil through transesterification process. Safflower oil methyl ester blended with diesel is used as a fuel for single cylinder diesel engine. Blend of $20 \%$ and $40 \%$ at compression ratio 17 and 18 are checked for the analysis of performance and emission of engine. A comparison has been made with the blend of biodiesel and diesel and pure diesel.

\section{Material and Methods}

The material used in this investigation was mainly for preparation of bio-diesel. Safflower oil was purchased from sarda oil mill, kadam wakwasti,Pune. To prepare bio diesel safflower oil has to go alkaline transesterification process. Methanol and Potassium hydroxide used for transesterification was purchased from Nutan Chemicals, bhosari, Pune.

\subsection{Transesterification}

It is a chemical process used for preparation of biodiesel from pure vegetable oil. A chemical reaction takes place between vegetable oil and alcohol in presence of catalyst to form ester and glycerol. The factors which affect the process are alcohol used, molar ratio of glycerides to alcohol, catalyst, reaction temperature, reaction time and water content of vegetable oils.

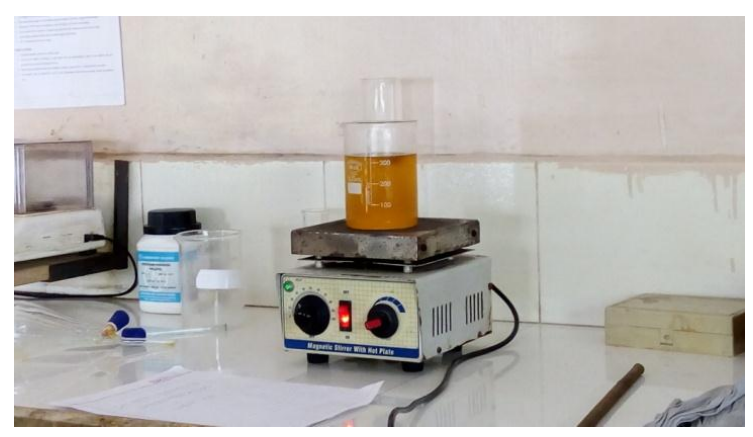

Fig.1Bio-diesel Preparation set up.

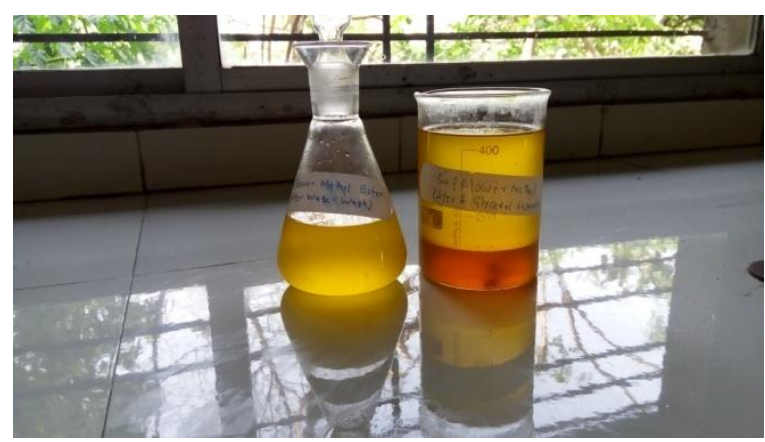

Fig.2Separation of bio-diesel and glycerin

In this investigation safflower oil is used as vegetable oil, methanol is used as alcohol and potassium hydroxide is used as catalyst. Initially $200 \mathrm{ml}$ of safflower oil was heated up to $50^{\circ} \mathrm{c}$ and it was mixed with $80 \mathrm{ml}$ of methanol and $3 \mathrm{gm}$ of $\mathrm{KOH}$. A magnetic stirrer with hot plate was used to stir the mixture continuously for two hours. After that mixture was cooled for 3 hours. Glycerol being heavy weight settles down in the separating funnel. In this way glycerol and ester gets separated. Again it was water washed and heated to $100 \mathrm{c}$ to remove any glycerol and moisture in the ester. Approximately $190 \mathrm{ml}$ of safflower oil methyl ester was obtained during this process.

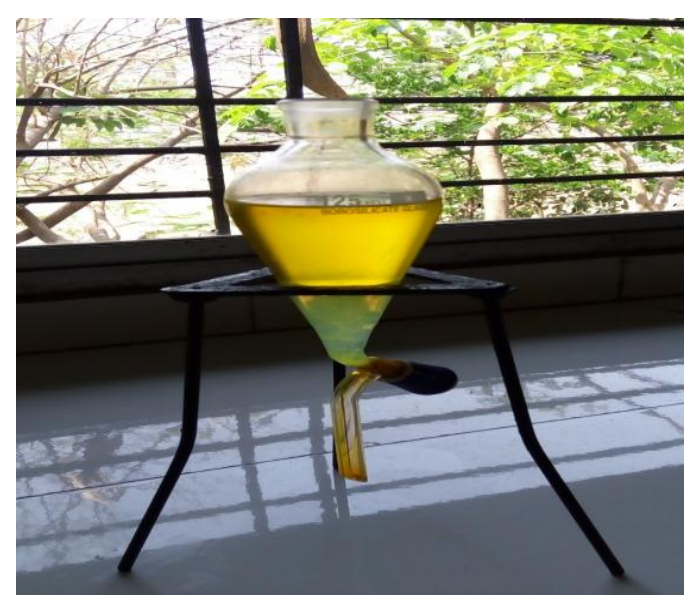

Fig.3 Water wash of bio-diesel

Table1 Properties of safflower oil and its blends

\begin{tabular}{|c|c|c|c|}
\hline Property & Diesel & B20 & B40 \\
\hline Density $\left(\mathrm{kg} / \mathrm{m}^{3}\right)$ & 810.7 & 818.4 & 833.2 \\
\hline $\begin{array}{c}\text { Calorific } \\
\text { value(kj/kg) }\end{array}$ & 42000 & 37000 & 34000 \\
\hline Specific gravity & 0.805 & 0.8129 & 0.8325 \\
\hline Flash point inं c & 54 & 75 & 83 \\
\hline Fire point inं c & 58 & 82 & 87 \\
\hline
\end{tabular}

\subsection{Experimental set up and Procedure}

In order to investigate the effects of safflower bio-diesel a single cylinder variable compression ratio diesel engine set up is used in the present work. Experiments were carried out for pure Diesel (B0), 20\% Bio Diesel (B20) and 40\% Bio Diesel (B40). For each blend, Compression ratios were to be varied in steps of 17 and 18. Matrix generated from the engine run was used for final result. For each test, engine load is varied from 0.5 $\mathrm{kg}$ to $9 \mathrm{~kg}$ in steps of $3 \mathrm{~kg}$.

The important operating parameters to note down are engine speed; brake power, fuel consumption, and cylinder pressure were measured. Significant engine performance parameters evaluated are Brake Specific Fuel Consumption (BSFC) and Brake Thermal Efficiency (BTE) for each blend.

Before start of new engine test, fuel blend from previous test left in the supply lines was consumed entirely by running engine idle for couple of minutes. Engine readings were reported only after steady state is achieved after running engine for few minutes further and by observing the exhaust gas temperatures. 


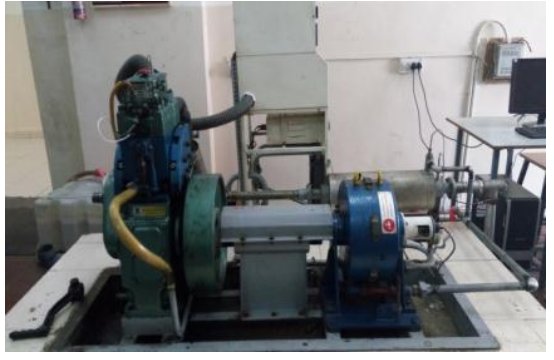

Fig.4 4-stroke single cylinder diesel engine

Table2Specification of engine used

\begin{tabular}{|c|c|}
\hline Engine Type & Four stroke diesel engine \\
\hline No of cylinders & 1 \\
\hline Rated Power & 3.5 kw@1500rpm \\
\hline Cylinder diameter & $87.5 \mathrm{~mm}$ \\
\hline Stroke length & $110 \mathrm{~mm}$ \\
\hline Connecting rod length & $234 \mathrm{~mm}$ \\
\hline Compression ratio vary & 12 to 18 \\
\hline Cylinder diameter & $20 \mathrm{~mm}$ \\
\hline Cooling & Water cooled \\
\hline
\end{tabular}

\section{Results and Discussions}

\subsection{Performance Parameters}

Performance Characteristics of the Engine like Specific Fuel Consumption (SFC) and Brake Thermal Efficiency (BTE) for each blend and effect of variation in Compression Ratio are calculated and plotted on graph. The fuel consumption characteristics of an engine are expressed in terms of specific fuel consumption in kilograms of fuel per kilowatt-hour. It reveals how good the engine performance is.

\subsubsection{Specific Fuel Consumption (SFC)}

Table3 Specific Fuel Consumption (kg/kwh)

\begin{tabular}{|c|c|c|c|c|c|c|}
\hline \multirow{2}{*}{ load } & \multicolumn{2}{|c|}{ B20 } & \multicolumn{2}{c|}{ B40 } & \multicolumn{2}{c|}{ Diesel } \\
\cline { 2 - 7 } & 17 CR & $18 \mathrm{CR}$ & $17 \mathrm{CR}$ & $18 \mathrm{CR}$ & $17 \mathrm{CR}$ & $18 \mathrm{CR}$ \\
\hline 0 & 3.89 & 4.64 & 3.95 & 3.76 & 4.38 & 4.59 \\
\hline 3 & 0.48 & 0.57 & 0.54 & 0.51 & 0.70 & 0.51 \\
\hline 6 & 0.35 & 0.35 & 0.34 & 0.35 & 0.29 & 0.35 \\
\hline 9 & 0.28 & 0.28 & 0.27 & 0.28 & 0.31 & 0.29 \\
\hline
\end{tabular}

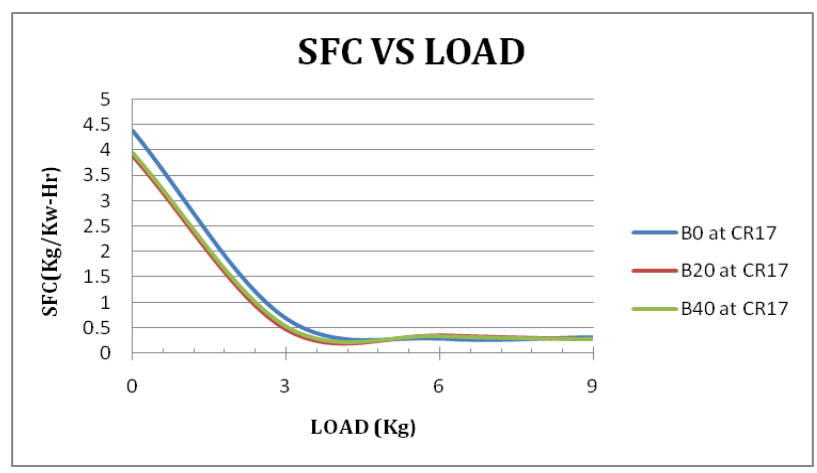

Fig.5 Variation of specific fuel consumption with loadat CR17
From graph it can be observed that, at compression ratio 17:1 specific fuel consumption (SFC) for blend B20 is minimum as compared from other blend and diesel. This advantage is significant at part loads and diminishes as the engine is run at full load and above.

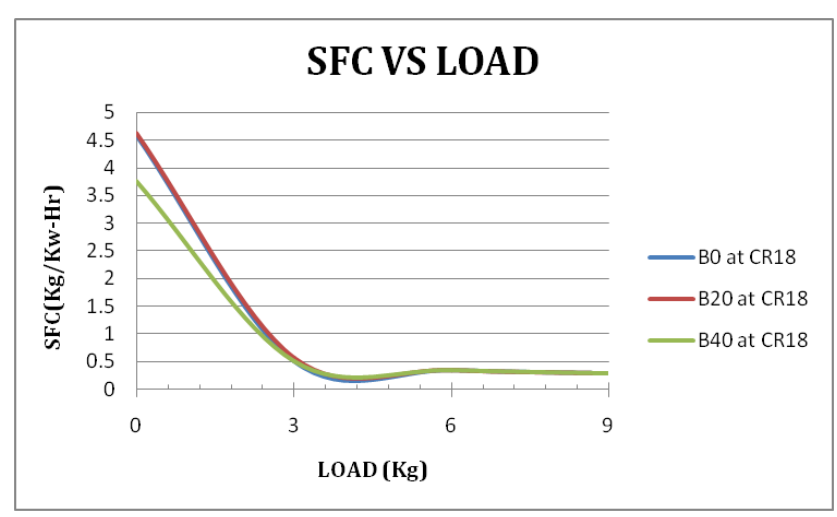

Fig.6 Variation of specific fuel consumption with load at CR18

At compression Ratio 18:1 specific fuel consumption (SFC) for blend B40 is minimum as compared from other blend and diesel. At no load condition, SFC reduces by $18 \%$. This advantage is significant at part loads and diminishes as the engine is run at full load and above.

\subsubsection{Brake Thermal Efficiency}

Table 4 Brake Thermal Efficiency (\%)

\begin{tabular}{|c|c|c|c|c|c|c|}
\hline \multirow{2}{*}{ load } & \multicolumn{2}{|c|}{ B20 } & \multicolumn{2}{c|}{ B40 } & \multicolumn{2}{c|}{ Diesel } \\
\cline { 2 - 7 } & $17 \mathrm{CR}$ & $18 \mathrm{CR}$ & $17 \mathrm{CR}$ & $18 \mathrm{CR}$ & $17 \mathrm{CR}$ & $18 \mathrm{CR}$ \\
\hline 0 & 2.2 & 1.85 & 2.17 & 2.28 & 1.96 & 1.87 \\
\hline 3 & 17.94 & 15.13 & 15.91 & 16.76 & 12.1 & 16.86 \\
\hline 6 & 24.32 & 24.36 & 25.33 & 24.37 & 29.1 & 24.72 \\
\hline 9 & 30.32 & 30.89 & 31.41 & 30.97 & 27.6 & 29.26 \\
\hline
\end{tabular}

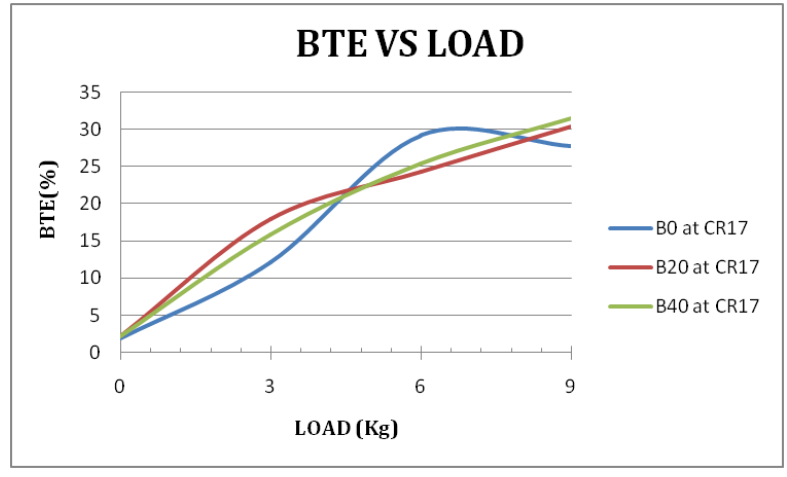

Fig.7Variation of Brake Thermal Efficiency with load at CR17

From the above graph it can be observed that at compression ratio $17: 1$ brake thermal efficiency (BTE)of B20 and B40 is better than diesel. BTE increases by approx $6 \%$ while running at half load condition. 


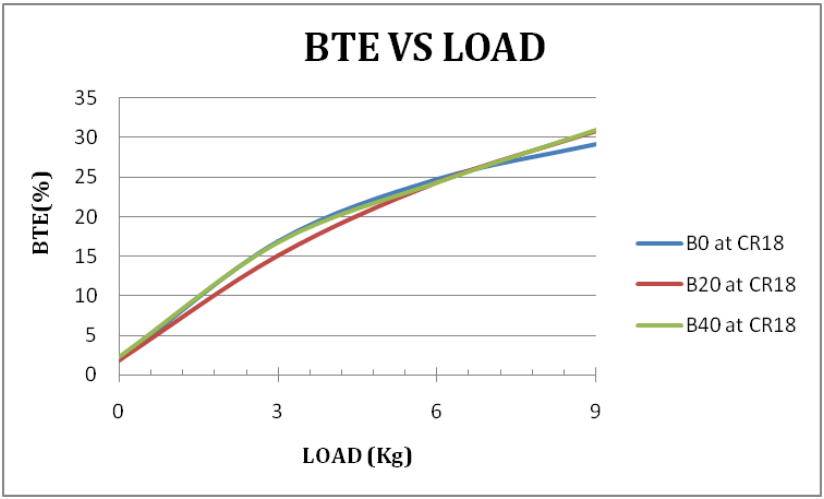

Fig.8Variation of Brake Thermal Efficiency with load at CR18

From the above graph it can be observed that at compression ratio 18:1 brake thermal efficiency of B40 is better than other blends and diesel. The change is marginal at all load condition.

\subsection{Emissions}

Emissions from both the blends and diesel were recorded using exhaust gas analyzer and a comparison has been made using graphical method for different load condition.

\subsubsection{Smoke Opacity}

Table 5 Smoke Opacity (\%)

\begin{tabular}{|c|c|c|c|c|c|c|}
\hline \multirow{2}{*}{ load } & \multicolumn{2}{|c|}{ B20 } & \multicolumn{2}{c|}{ B40 } & \multicolumn{2}{c|}{ Diesel } \\
\cline { 2 - 7 } & $17 \mathrm{CR}$ & $18 \mathrm{CR}$ & $17 \mathrm{CR}$ & $18 \mathrm{CR}$ & $17 \mathrm{CR}$ & $18 \mathrm{CR}$ \\
\hline 0 & 5.1 & 11.7 & 8.3 & 6.2 & 5.6 & 7.6 \\
\hline 3 & 11.3 & 13.6 & 15.2 & 8.6 & 17 & 18 \\
\hline 6 & 16.3 & 21.3 & 20.5 & 18.6 & 22.7 & 24 \\
\hline 9 & 19.5 & 26.6 & 21.2 & 21.8 & 41 & 48 \\
\hline
\end{tabular}

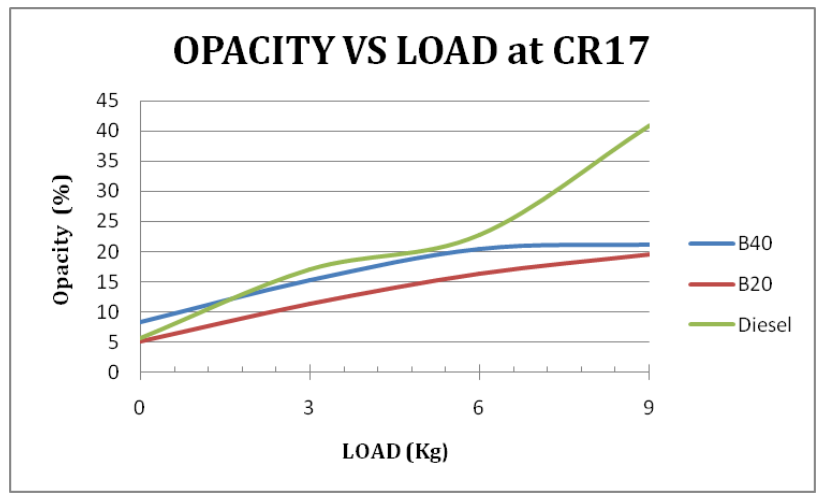

Fig.9Variation of Opacity with load at CR17

From the above graph it can be observed that the smoke opacity for diesel is more as compared from other blends. For B40 smoke opacity is minimum.

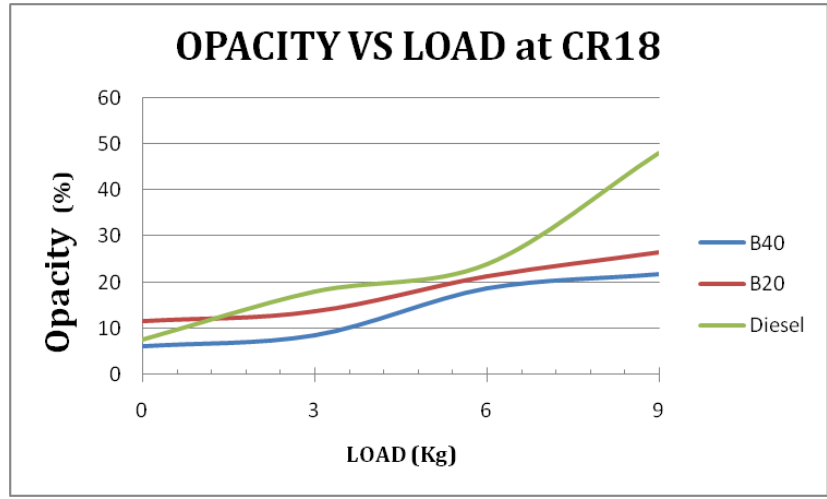

Fig.10Variation of Opacity with load at CR18

At compression ratio 18:1 also the smoke opacity for blend B40 is minimum.

\subsection{2 $\mathrm{CO}_{2}$ Emissions}

Table $6 \mathrm{CO}_{2}$ Emissions (\% vol)

\begin{tabular}{|c|c|c|c|c|c|c|}
\hline \multirow{2}{*}{ load } & \multicolumn{2}{|c|}{ B20 } & \multicolumn{2}{c|}{ B40 } & \multicolumn{2}{c|}{ Diesel } \\
\cline { 2 - 7 } & $17 \mathrm{CR}$ & $18 \mathrm{CR}$ & 17CR & $18 \mathrm{CR}$ & $17 \mathrm{CR}$ & $18 \mathrm{CR}$ \\
\hline 0 & 1.31 & 1.81 & 1.28 & 1.4 & 1.51 & 1.91 \\
\hline 3 & 1.54 & 1.74 & 1.73 & 1.93 & 2.57 & 2.75 \\
\hline 6 & 1.35 & 1.66 & 2.14 & 1.79 & 4.61 & 5.21 \\
\hline 9 & 1.59 & 0.95 & 2.22 & 1.55 & 5.23 & 5.28 \\
\hline
\end{tabular}

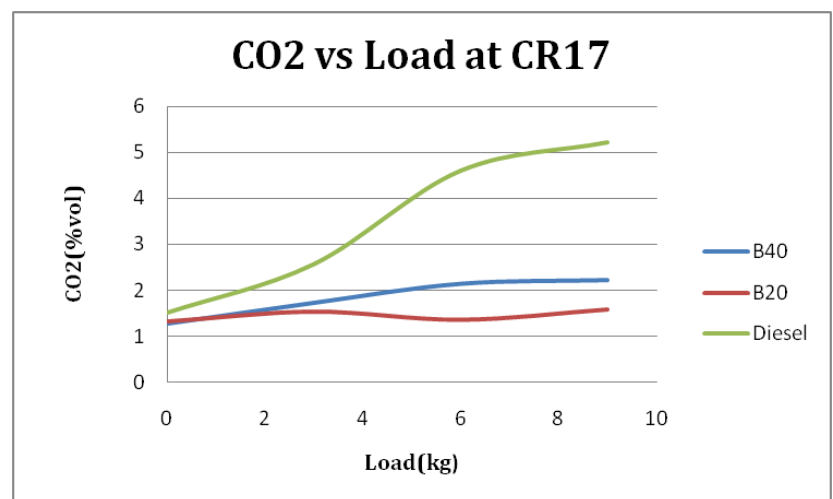

Fig.11Variation of $\mathrm{CO}_{2}$ with load at CR17

At compression ratio $17: 1$, higher $\mathrm{CO}_{2}$ emissions are observed for diesel. At all the load conditions, all the blends have lesser $\mathrm{CO}_{2}$ emissions than that of diesel. At full load, $\mathrm{CO}_{2}$ emissions reduce by $70 \%$ from diesel in case of blend $\mathrm{B} 20$. In the operating range, $\mathrm{CO}_{2}$ emissions are more for blend B40.This may due to the complete oxidation of carbon particles present in the fuel.

At compression ratio 18:1 also higher $\mathrm{CO}_{2}$ emissions are observed for diesel. At all the load conditions, all the blends have lesser $\mathrm{CO}_{2}$ emissions than that of diesel. At full load condition, $\mathrm{CO}_{2}$ emissions reduce by $82 \%$ from diesel in case of blend $\mathrm{B} 20$. In the operating range, $\mathrm{CO}_{2}$ emissions are more for blend B40.This may due to the complete oxidation of carbon particles present in the fuel. 


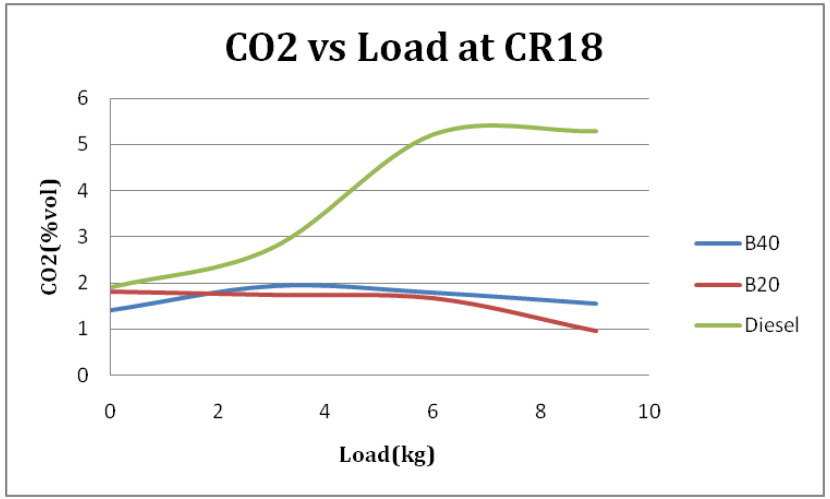

Fig.12Variation of $\mathrm{CO}_{2}$ with load at CR18

3.2.3 NOx Emissions

Table 7 NOx Emissions (ppm)

\begin{tabular}{|c|c|c|c|c|c|c|}
\hline \multirow{2}{*}{ load } & \multicolumn{2}{|c|}{ B20 } & \multicolumn{2}{c|}{ B40 } & \multicolumn{2}{c|}{ Diesel } \\
\cline { 2 - 7 } & $17 \mathrm{CR}$ & $18 \mathrm{CR}$ & $17 \mathrm{CR}$ & $18 \mathrm{CR}$ & $17 \mathrm{CR}$ & $18 \mathrm{CR}$ \\
\hline 0 & 58 & 87 & 57 & 78 & 72 & 95 \\
\hline 3 & 87 & 111 & 96 & 124 & 153 & 160 \\
\hline 6 & 101 & 139 & 149 & 146 & 367 & 375 \\
\hline 9 & 142 & 178 & 222 & 189 & 527 & 550 \\
\hline
\end{tabular}

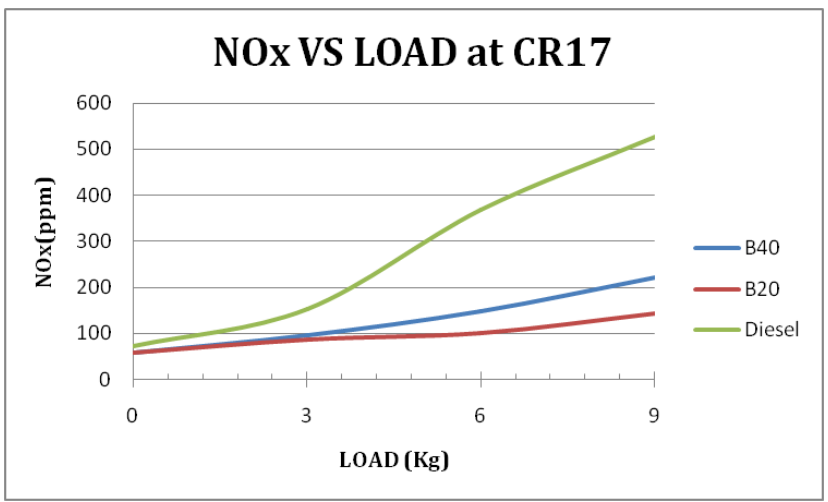

Fig.13Variation of NOx with load at CR17

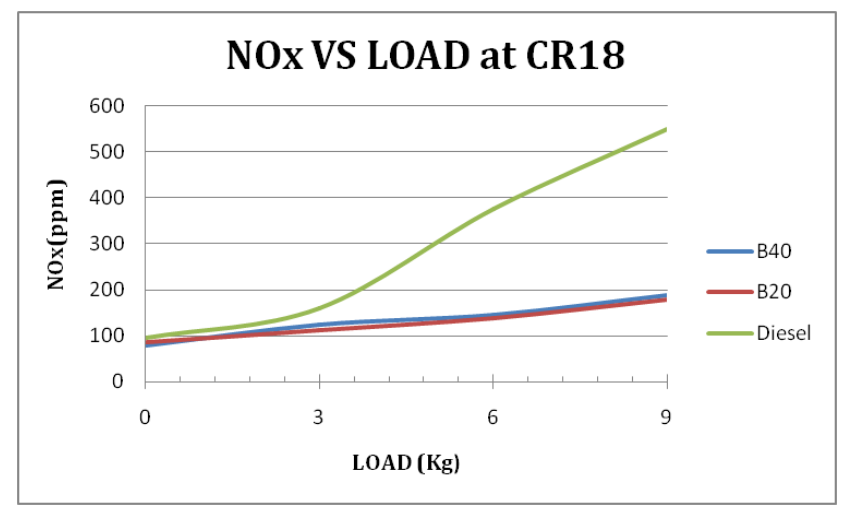

Fig.14Variation of $\mathrm{NO}_{\mathrm{x}}$ with load at CR18

At compression ratio 17:1 Higher NOx emissions are observed for diesel. At all the load conditions, all the blends have lesser NOx emissions than that of diesel. In fact it reduces by almost $73 \%$ at full load condition for blend B20. In the operating range, NOx emissions are more for blend B40. This may due to the increase in temperature inside the engine cylinder because of complete combustion of fuel.

At compression ratio 18:1 also higher $\mathrm{NOx}$ emissions are observed for diesel. At all the load conditions, all the blends have lesser NOx emissions than that of diesel. In this case NOx emissions reduce by almost $68 \%$ at full load condition for blend B20. In the operating range, NOx emissions are more for blend B40. This may due to the increase in temperature inside the engine cylinder because of complete combustion of fuel.

\subsubsection{CO Emissions}

Table 8 CO Emissions (\%vol)

\begin{tabular}{|c|c|c|c|c|c|c|}
\hline \multirow{2}{*}{ load } & \multicolumn{2}{|c|}{ B20 } & \multicolumn{2}{c|}{ B40 } & \multicolumn{2}{c|}{ Diesel } \\
\cline { 2 - 7 } & $17 \mathrm{CR}$ & $18 \mathrm{CR}$ & $17 \mathrm{CR}$ & $18 \mathrm{CR}$ & $17 \mathrm{CR}$ & $18 \mathrm{CR}$ \\
\hline 0 & 0.34 & 0.24 & 0.23 & 0.21 & 0.29 & 0.29 \\
\hline 3 & 0.19 & 0.17 & 0.17 & 0.15 & 0.23 & 0.23 \\
\hline 6 & 0.22 & 0.18 & 0.21 & 0.1 & 0.22 & 0.22 \\
\hline 9 & 0 & 0.2 & 0 & 0.08 & 0.2 & 0.20 \\
\hline
\end{tabular}

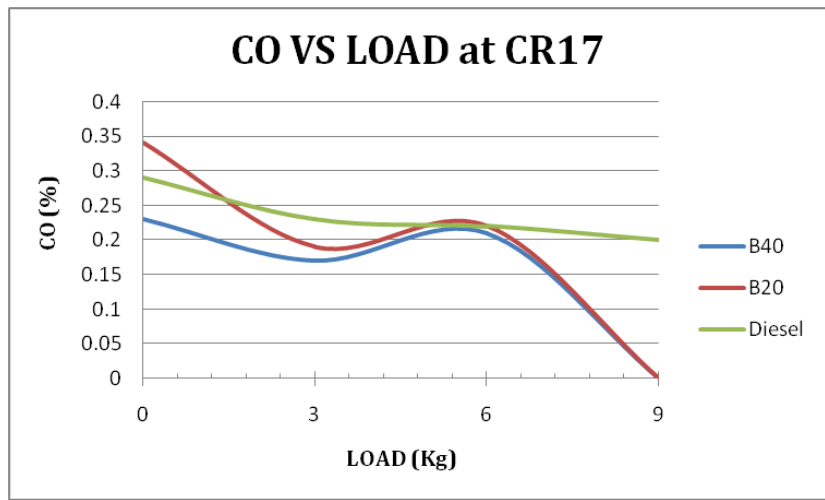

Fig.15Variation of CO with load at CR17

At compression ratio 17:1, higher CO emissions are observed for diesel. At no load condition blend B20 has more emissions than diesel while at half load and full load it reduces by big margin for both the blends. This may due to more availability of oxygen for complete combustion of fuel particles.

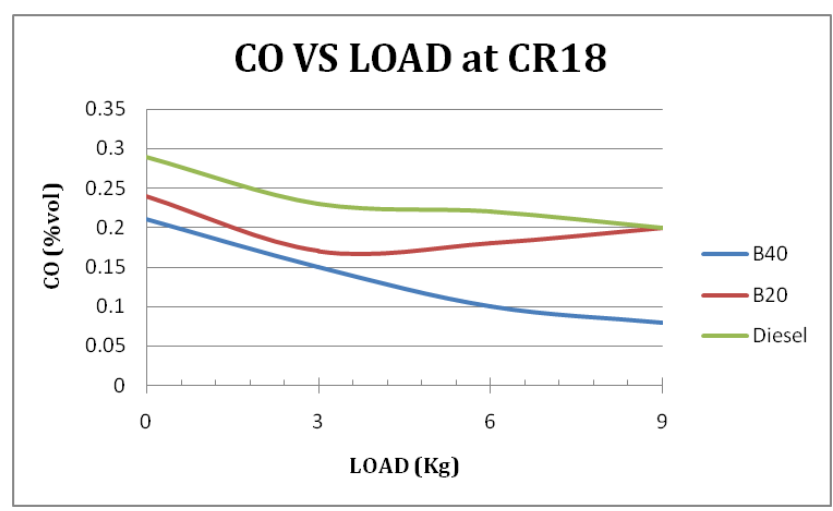

Fig.16Variation of CO with load at CR18 
At compression ratio 18:1, blends show less CO emissions than diesel. It reduces by $60 \%$ for blend B 40 at half load condition. This may due to more availability of oxygen for complete combustion of fuel particles.

\subsubsection{Hydrocarbon Emissions}

Table 9 Hydrocarbon Emissions(ppm)

\begin{tabular}{|c|c|c|c|c|c|c|}
\hline \multirow{2}{*}{ load } & \multicolumn{2}{|c|}{ B20 } & \multicolumn{2}{c|}{ B40 } & \multicolumn{2}{c|}{ Diesel } \\
\cline { 2 - 7 } & $17 \mathrm{CR}$ & $18 \mathrm{CR}$ & $17 \mathrm{CR}$ & $18 \mathrm{CR}$ & $17 \mathrm{CR}$ & $18 \mathrm{CR}$ \\
\hline 0 & 15 & 8 & 7 & 7 & 12 & 10 \\
\hline 3 & 11 & 9 & 8 & 8 & 14 & 13 \\
\hline 6 & 12 & 10 & 9 & 9 & 19 & 17 \\
\hline 9 & 12 & 9 & 10 & 9 & 25 & 22 \\
\hline
\end{tabular}

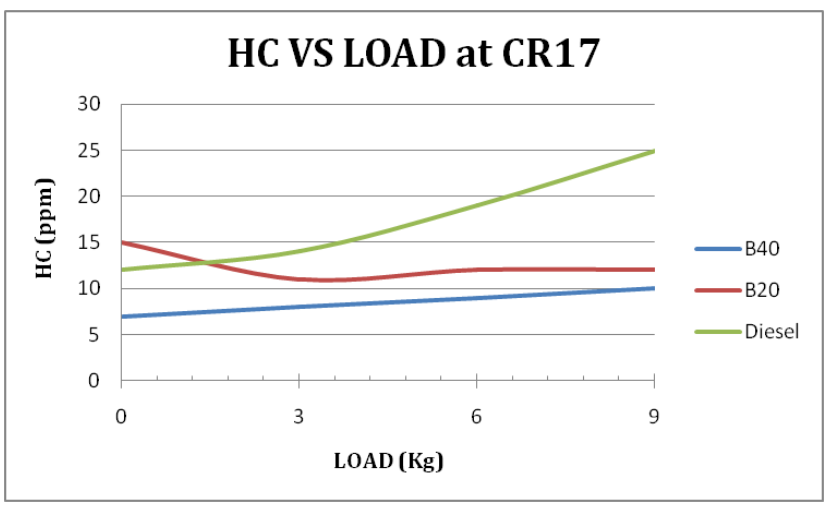

Fig.17Variation of HC with load at CR17

At compression ratio 17:1, higher $\mathrm{HC}$ emissions are observed for diesel. At all the load conditions, all the blends have lesser $\mathrm{HC}$ emissions than that of diesel except for blend B20 which shows more ppm than diesel. At full load condition HC emission reduces by 60 $\%$ for blend B40. This may be due to an increase in residual gas temperature within the cylinder and decrease in flame quenching thickness at higher loads in the engine.

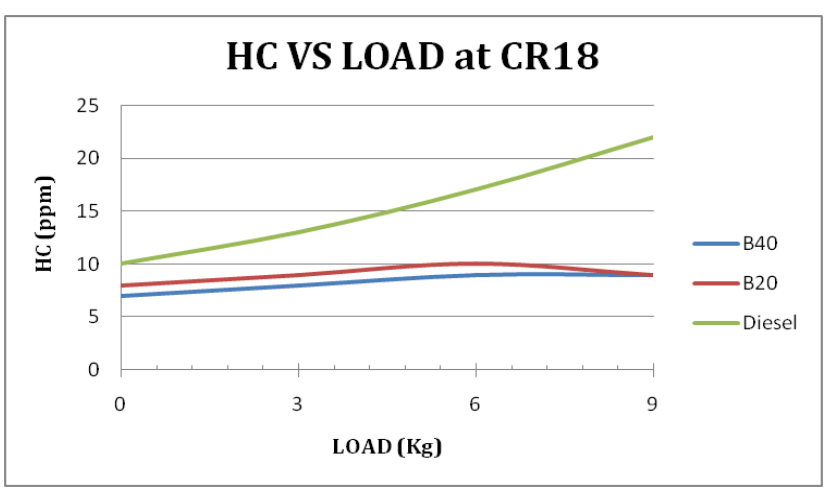

Fig.18Variation of HC with load at CR18

At compression ratio 18:1, also all the blends have less $\mathrm{HC}$ emissions than diesel. At full load it reduces by $59 \%$ for blend B40. This may be due to an increase in residual gas temperature within the cylinder and decrease in flame quenching thickness at higher loads in the engine.

\section{Conclusions}

1) At half load and full load, Specific fuel consumption (SFC) for blend B40 at compression ratio 18:1 is marginally less than blend B20 and Pure diesel. Also it reduces to $18 \%$ from diesel at no load condition.

2) At all load conditions, brake thermal efficiency for blend B40 at compression ratio 18:1 and 17:1 is better than blend B20 and Pure Diesel. In fact it increases by $14 \%$ running at full load at compression ratio 17:1

3) At all load conditions and for both compression ratios,smoke opacity for blend B40 is less.

4) At all load conditions, $\mathrm{CO}_{2}$ emission for diesel is more than other blends. At compression ratio 18:1, emissions for blend B20 reduce by $82 \%$ at full load.

5) At all the load conditions, all the blends have lesser NOx emissions than that of diesel. Blend B20 has the lowest emissions of Nitrogen Oxide gas.It reduces by $68 \%$ while operating at $18: 1$ compression ratio.

6) Almost at all the load conditions, all the blends have lesser $\mathrm{CO}$ emissions than that of diesel. At full load condition HC emission reduces by $60 \%$ for blend B40 at 18:1 compression ratio.

7) At compression ratio 17:1 and 18:1 higher HC emissions are observed for diesel at all load condition. At full load condition $\mathrm{HC}$ emission reduces by $60 \%$ for blend $\mathrm{B} 40$.

\section{Future Scope}

1) This work can be extended by investigating the effects on performance and emissions by taking different compression ratio and different biodiesel.

2) Results can be varied by changing the injection timing of fuel.

3) By adding EGR to engine percentage of flow of EGR can be determined.

4) Same oil can be used to check the combustion, performance and emission characteristics for multi cylinder diesel engine.

5) Different additives can be used in safflower oil methyl ester to increase the performance of the engine.

6) Further analysis can be done using computational fluid dynamics.

\section{References}

Dr. A. Sharma, Mr. G. Sharma, Ms. M. Sharma and Ms P. Gupta, (2012), Impact Of Crude Oil Price On Indian Economy, International Journal of Social Sciences \& Interdisciplinary Research, Vol.1 pp. 95-98.

Dr. K. R. Bandyopadhyay, (2015), Bio-fuel Promotion in India for Transport: Exploring the Grey Areas, Policy Brief-The Energy and Resources Institute (TERI) February edition.

K. Vinukumar, (2013), Production of Bio-Diesel Used In Diesel Engines, Innovare Journal of Eng. \& Tech, Vol. 1, pp. 5-7. 
K. D. Chaudhari, N. P. Salunke and V. K. Suryawanshi ,(2016), Performance Analysis of Variable Compression Ratio Diesel Engine using Methyl Ester of Cotton Seed Oil blend with Diesel, Elixir international journal, vol. 91, pp. 6-15.

A. S. Kumari, C. H. Penchalayya and A.V. Sita Rama Raju, (2013), Performance Evaluation Of Diesel Engine With Safflower Oil , Journal of Engineering Studies and Research, Vol. 19 pp. 63-69.

S Ramalingam, S. Rajendran and P Ganesan, (2015), Influence Of Injection Timing And Compression Ratio On Performance, Emission And Combustion Characteristics of Annona Ethyl Ester Operated Diesel Engine, Alexandria Engineering Journal, vol.54, pp. 295-302.
H Fukuda, A Kondo and H Noda, (2001), Biodiesel production by transesterification of oils, Journal of bio science and bioengineering, vol. 92, pp. 405-416.

Dr. S. S. Ragit. S. K. Mohapatra, K. kundu and P. Gill (2011) Optimization of neem methyl ester from transesterification process and fuel characterization as a diesel substitution Biomass and Bio-energy, vol. 35 issue 3 pp. 1138-1144.

Dr. S. S. Ragit and S. K. Mohapatra, (2011), Comparative study of engine performance and exhaust emission characteristics of a single cylinder 4-stroke CI engine operated on the esters of hemp oil and neem oil, Indian Journal of Engineering and Materials Sciences, vol. 18, pp. 204-210. 